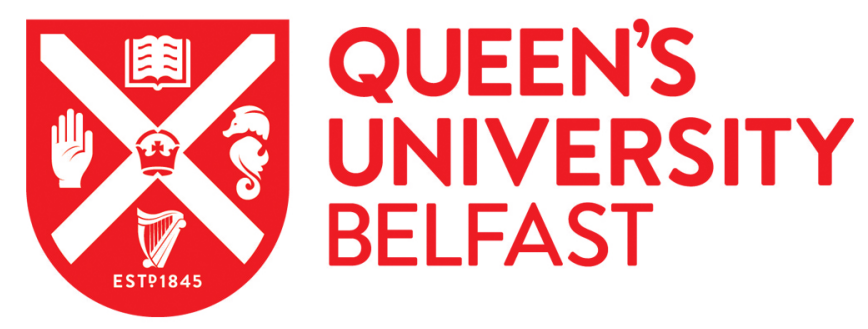

\title{
Using Audio-visual Presentation to Teach Global Mindedness in Social Work Education
}

Moriarty, J., Anand, J., Davidson, G., Das, C., \& Pinkerton, J. (2016). Using Audio-visual Presentation to Teach Global Mindedness in Social Work Education. Journal of Practice Teaching and Learning, 14(1), 19-37. https://journals. whitingbirch.net/index.php/JPTS/article/view/882

Published in:

Journal of Practice Teaching and Learning

Document Version:

Peer reviewed version

Queen's University Belfast - Research Portal:

Link to publication record in Queen's University Belfast Research Portal

Publisher rights

(c) 2016 Whiting \& Birch

\section{General rights}

Copyright for the publications made accessible via the Queen's University Belfast Research Portal is retained by the author(s) and / or other copyright owners and it is a condition of accessing these publications that users recognise and abide by the legal requirements associated with these rights.

Take down policy

The Research Portal is Queen's institutional repository that provides access to Queen's research output. Every effort has been made to ensure that content in the Research Portal does not infringe any person's rights, or applicable UK laws. If you discover content in the Research Portal that you believe breaches copyright or violates any law, please contact openaccess@qub.ac.uk. 
“Using Audio-visual Presentation to Teach Global Mindedness in Social Work Education”

John Moriarty, PhD, Research Fellow, Administrative Data Research Centre for Northern Ireland, Queen’s University Belfast Centre for Public Health, Royal Victoria Hospital, Grosvenor Road, Northern Ireland, BT12 6BA, email: j.moriarty@qub.ac.uk Janet Carter-Anand, PhD, Professor of International Social Work, Faculty of Social Sciences and Business Studies, University of Eastern Finland, Finland Gavin Davidson, PhD, Senior Lecturer, School of Sociology, Social Policy and Social Work, Queen's University Belfast, Northern Ireland

Chaitali Das, PhD, Policy and Student Support Coordinator, Jacobs University, Bremen, Germany

John Pinkerton, PhD, Professor, School of Sociology, Social Policy and Social Work, Queen’s University Belfast, Northern Ireland

\section{Article Summary}

Direct experience of social work in another country is making an increasingly important contribution to internationalising the social work academic curriculum together with the cultural competency of students. However at present this opportunity is still restricted to a limited number of students. The aim of this paper is to describe and reflect on the production of an audio-visual presentation as representing the experience of three students who participated in an exchange with a social work programme in Pune, India. It describes and assesses the rationale, production and use of video to capture student learning from the Belfast/Pune exchange. We also describe the use of the video in a classroom setting with a year group of 53 students from a younger cohort. This exercise aimed to stimulate students' curiosity about international dimensions of social work and add to their awareness of poverty, social justice, cultural competence and community social work as global issues. Written classroom feedback informs our discussion of the technical as well as the pedagogical benefits and challenges of this approach. We conclude that some benefit of audio-visual presentation in helping students connect with diverse cultural contexts, but that a complementary discussion challenging stereotyped viewpoints and unconscious professional imperialism is also crucial. 
Keywords: international social work; international student exchange; cultural competence; audio-visual pedagogy; India; Northern Ireland

The film project described was funded thought a Higher Education Academy grant as part of a project to evaluate the current international exchange initiatives undertaken within Social Work at QUB (Janet CarterAnand, Chaitali Das and Gavin Davidson). This project received ethical approval from the QUB ethics research committee in 2012. The employment of a research assistant/producer (John Moriarty) was financed under this grant. 


\section{Introduction and Context}

This article discusses the development and evaluation of an audio-visual presentation to promote undergraduate social work students' global-mindedness. This case study is used to demonstrate how international student exchange opportunities, taken up by even just a few students, can be used to help internationalise the mainstream curriculum of a social work course, as well as the challenges inherent in such an approach. The international student exchange project was conceived in the context of the interaction of a range of factors including: increased emphasis on internationalisation in higher education including social work; technological advances facilitating communication and education across geographical boundaries; and an increased openness within Northern Ireland to embracing international practices as a stimulus to positive change in a post-conflict society. The learning tool described in this article was a video compiling images and reflective commentary produced by three undergraduate social work students at Queen’s University Belfast during their participation in an exchange exercise with the Karve Institute of Social Studies in Pune, India. The video was shown to a later undergraduate cohort of 53 students who each completed a self-administered survey which invited reflections on the video's lessons and on the video's value as a learning tool.

\section{Promoting Global Mindedness in Social Work via Student Exchanges}

Cultural competence is fundamental to anti-oppressive social work practice (Abrams and Moio, 2009) and was a direct response to increasing cultural and ethnic diversity (Chau et al., 2010) of British society as the result of global immigration and migration. The most common approach to cultural competence in social work education focuses on the student's acquired knowledge of different cultural values, beliefs and behaviours (Laird, 2008). This approach has been extensively critiqued (Harrison \& Turner 2011; Ben-Ari and Strier, 2010) given its tendency to translate cultural difference into forms of 'othering' or 'exoticism'. A more critical approach to cultural competence promotes consciousness of how oppression, privilege, inequality and social injustice (Kumagai, et al. 2009; Williams and Soydan, 2005; Betancourt 2003) is embedded in dominant cultural practices and structures. In this paper we use the concept of global mindedness, or the capacity to reflect upon how difference is defined by historical, political, social, cultural and ethnic constructs and contexts. As part of internationalising the social work curriculum, students should be encouraged to question the reification of culturalism (Jamrozik, 2009) that allows for the 
continuation of discriminatory, abusive and oppressive practices (Ife, 2008, p. 79) across different global contexts.

In the UK there exist multiple economic, research and quality drivers for promoting internationalisation in higher education. Lorenz has asserted that "all social work is enmeshed in the global processes of change” (1997, p.2) and it has been argued that there may be many pedagogical benefits of internationalising social work curricula (CarterAnand \& Clarke, 2009; Healy, 2008; Healy \& Link 2012). For example, Carter-Anand and Clarke (2009) highlight that, in the United States, the Council on Social Work Education requires that social workers must understand institutions, oppression and social systems within a global context (2001). In the United Kingdom, the Higher Education Academy has suggested that "Internationalising the curriculum involves providing students with global perspectives of their discipline and giving them a broader knowledge base for their future careers... [It] can also help to provide them with a set of values and skills to operate in diverse cultural environments; skills often labelled 'cultural or intercultural competencies' or 'cross-cultural capabilities'” (2014, p.2).

However, Gray cautions that increasing international or global approaches to social work have the potential for professional imperialism and for undermining the development of indigenised social work (Gray, 2005). Gray argues for a balanced and positive approach to social work’s engagement with globalisation which “enables indigenisation, retains universals yet avoids imperialism” (p. 231). Her challenge to social work educators is to explore new ways of opening students to diverse cultural contexts so as to equip them for professional practice in a global context. Merrill and Frost (2011) have identified that providing the benefits of internationalisation within social work education may present specific challenges including the demographics of social work students and the demands of professional accreditation, and so may require a range of approaches.

The challenge of promoting global mindedness amongst students has added dimensions in Northern Ireland. First, social work has to contend with the legacy of a sectarian driven violent politics, euphemistically referred to locally as 'The Troubles' (Campbell et al 2012). Developments during the Troubles encouraged a narrowly defined technocratic, statutory professionalism and inhibited the development of progressive, international approaches to practice (Houston, 2008; Pinkerton \& Campbell, 2002). However, the emergence of a post-conflict society and changing social and political conditions in Northern Ireland are creating new opportunities and possibilities for social work students 
to share their experiences as well as benefit from exposures to other cultural issues and contexts (Das \& Carter-Anand, 2014). Second, the economic downturn of recent years has meant that some Northern Irish students have to seek employment in other countries. Knowledge of the global context, skills to engage with a diverse range of clients and values that are globally inclusive have implications for students' future employment opportunities and are therefore increasingly relevant to social work education.

One avenue educators have explored is that of offering programmes through which students travel abroad to observe and engage with social work education and practice in an unfamiliar context (Lager \& Mathiesen 2012; Link \& Vogrincic 2012). Ferguson and Smith argue that international placements offer students additional contexts for understanding the critical and radical potential of social work practice, not always apparent or accessible to students in the current Euro-centric, neo-liberal culture prevalent in UK health and social care services (2012). By being physically immersed in a different context, students are exposed to different ways of thinking and knowing about the world and constantly have to rework previously held values, assumptions and theories of social work practice and education to make sense of their experiences (Fook, 2002). Furthermore, international exchanges increase participants' opportunities to test out critical theory and ideas in practice. This represents a particularly important opportunity for students, such as those in the UK, where placements are tightly regulated within the constraints of a narrowly defined set of technical competencies. Fook and Askeland (2007) argue that without such opportunities it is unlikely that students will feel confident or competent enough to integrate such critical perspectives into their practice as qualified practitioners particularly where such perspectives run against the grain of employer expectations. Given the challenges faced by the social work profession in the UK (Jones 2014) and particularly within Northern Ireland (DHSSPS 2013), it seems pressing to include international practice settings among those available to students as part of their professional development. Such an outward-facing approach invites students to consider, in particular, the experience of fellow students, practitioners and educators who work in other national contexts and who seek to construct a social work rooted in social justice, better able to address issues of poverty, inequality and oppression with limited state funded resources.

In addition to enhancing critical skills, international experience also opens students up to the possibility of employment in other countries. International social work underpins many 
efforts led by the United Nations and of international Non-Governmental Organisations (Cox \& Pawar, 2006). Other reasons why students may be motivated to undertake overseas exchanges: fascination with other cultures include: links with or interest in a particular country; wanting to make a difference or wanting to give something back to the countries visited (Wehbi, 2008).

Meritorious though it may be to drive towards accepting global-mindedness, responding to the challenge is no easy task. Healy and Link point out that "developing new curricula for social work programs and modifying existing priorities can be daunting tasks” (p. 330). Developments do not necessarily follow a straight-forward path from the setting of new goals and learning outcomes, such as enhancing international social work education, to action. Scarcity of individual and institutional resources will necessarily restrict the number of students who can experience international contexts first-hand. Also, diseconomies of scale impose themselves at a certain point: once a visiting group passes a certain size, the scope for meaningful engagement shrinks. This leaves educators with the challenge of how to ensure that the learning of students directly involved in international programmes is shared with members of their cohort and with future cohorts. Small, opportunistic developments, such as described in this paper, may prove significant in moving a school programme towards a culture of internationalisation.

Video as pedagogical tool in social work education

As with all of education, the teaching of social work is being shaped by the digital age (Regan \& Youn, 2008). These technological advances have created a new range of possibilities for enabling international travel, collaboration, communication and dissemination (Payne \& Askeland, 2008). Examples include: provision of distance learning and supplemental online material via recorded classes, and other asynchronous material (Ballantyne, 2008; Levin, Whitsett, \& Wood, 2013; Okech, Barner, Segoshi, \& Carney, 2014); use of filmed vignettes in conjunction with verbal instruction and discussion (Ballantyne, 2008; Duffy 2013); and the use of video feedback in monitoring and modelling students’ own behaviour and practical skill (Bolger, 2014; Fukkink, Trienekens, \& Kramer, 2011) . 
Movements towards digital learning platforms and internationalisation would seem from the outset to be kindred. An advantage of a digital resource is its ability to transcend borders (Carter-Anand \& Clarke, 2009; Payne \& Askeland 2008). Thus, first-hand experiences can be captured and shared with persons at a great distance. However, one risk of this approach is that, if a person in region A has no a priori understanding of the cultural milieu of region $B$, their ability to make sense of any individual narrative, vignette, image or event may be limited or subject to distortion. Hence, the conclusions the person in region A draws may more saliently reflect their affinity to their own culture than any newfound understanding of the culture of region B that they are experiencing remotely. This would undermine educators' aims of challenging persistent ethnocentric professional (Das \& Carter-Anand, 2014). Social work educators need to find a mechanism for acknowledging and managing this paradox.

This paper shares one attempt to share students' international practice via audio-visual presentation. This has been incorporated into an ongoing international exchange initiative aimed at raising undergraduate students' appreciation of international dimensions of social work. How the work of the exchange students was captured through script and visuals, and later disseminated among their fellow students, is first described. The process of evaluation and gathering reflections from students who viewed the video on its quality and usefulness is then presented.

\section{Capturing the Exchange}

\section{Background}

A student exchange between the Karve Institute of Social Work in Pune, India and Queen's University Belfast (QUB) Social Work programmes took place in 2011 (described in Das \& Carter-Anand, 2014). Over the course of the exchange, participants produced approximately 300 digital photographs depicting the QUB visit to Pune and approximately 50 photographs of the Karve visit to Belfast. Following this exchange, the QUB exchange participants presented a seminar outlining their critical reflections on their time in Pune, which was recorded on video. They also provided video feedback to organisers of the exchange, along with participating staff from both institutions. They then collaborated with the organising team to produce a digital audio-visual presentation, capturing the experiences and reflections of exchange participants, with the aim of raising the profile of internationalisation efforts and of demonstrating globally-minded social work to students. 


\section{The Production Process}

The production team emanated from the mentoring team which oversaw the original exchange. In addition, a postgraduate student (first author) with experience of producing digital representations of research, including collaborations with social work staff, was recruited to lead the production.

In initial project planning, it was decided that presentation would take the format of a slideshow drawn from the participants’ photographs, with an accompanying recorded commentary, reflecting the insights of exchange participants. Along with the photographic archive, the previously recorded reflections of exchange participants were thoroughly audited by the production team, identifying key themes and events for inclusion in the commentary script. The three exchange students gave their permission for a commentary script to be written based on their reflections and seminar presentation. They later helped edit and record the script.

The production team storyboarded a sequence of photographs capturing key themes and events. From the photographs of Pune, three focal points emerged: observing social workers embedded in communities of manual labourers; provision of shelter to homeless young people; and the creative learning environment at the Karve Institute. As fewer photographs existed of Belfast-hosted phase, this section was shorter and gave an overview of participants' visitations to mental health treatment facilities and their meetings with Members of the Local Assembly in Stormont. The script was drafted and developed with specific images selected to match the timing and themes of the narrative. Commentary was recorded in studio and a musical bedding track was supplied by a local group known to the production team (a simple guitar-based instrumental).

The final cut is 6 minutes in duration, contains a series of still images of between 3-5 seconds in duration with background music and commentary. A copy is held on QUB servers and can be viewed through a page within the QUB Social Work website dedicated to "International Social Work" ${ }^{1}$. It is accompanied by written descriptions of globally minded approaches to social work produced by the mentoring team.

${ }^{1}$ http://www.qub.ac.uk/schools/SchoolofSociologySocialPolicySocialWork/Education/InternationalSocialWork/ \#d.en.386257 


\section{Themes Addressed in the Script}

A significant challenge to the production team was maintaining the integrity and ethos of the initial project. In creating a narrative, it is necessary to simplify the experience. However, if this comes at the expense of important nuance, there is a risk that what is disseminated might serve to enhance, rather than challenge, stereotyped views of “deprivation” and “deprived” systems of practice. Before and during the exchange, much training and discussion was carried out to equip the students with critical reflexive tools to combat such normative judgements. Mindful of this challenge, the script was constructed to avoid loaded references to deprivation.

The following are sample extracts from the description of Pune, under each of the major themes identified by students:

1. Lived realities of social work practice and learning in Pune:

"Many social work students told us about their plans to take personal financial risks to set up new NGOs after their studies to deal with problems in their own areas. This underlined for us the personal and vocational journey which many Indian social workers embark upon”;

2. The value of exchange in building critical reflective skills:

"The reciprocal dimension of the exchange was of great importance. No system is perfect, but all practitioners stand to benefit from being observed with fresh eyes and having their assumptions challenged. While undoubtedly the challenges to social workers are different depending where you are in the world, this exchange highlighted some of the values which social workers in any region can aspire to";

3. Students' own reflections:

"The example of the Karve students made me appreciate many of the advantages of social work in the UK, and also aware of things we can do better and more often, such as advocating for the rights of service users.”

\section{Dissemination and Teaching Applications}

The production has been used and as part of conference presentations to the Higher Education Authority, the Northern Ireland Social Work Associations, World Social Work Day 2013 celebrations, and at an International Social Work Conference at the Karve Institute. It is also being used as a teaching tool in modules on "Issues in Contemporary Social Work" and "Social Work in Context” and in training around cultural sensitivity and anti-oppressive practice. 


\section{Feedback and Reflections}

Feedback was sought from second year QUB social work students who viewed the video in the course of their "Contemporary Issues in Social Work” module. All students belonged to the year behind that of the exchange participants and therefore were not enrolled during the year the exchange visits took place.

The students provided feedback immediately after viewing the video via anonymous evaluation forms under several open-ended headings, such as: "list three things you have learnt from the video"; "list three things that you liked about the video"; and "list three things that you would change about the video”. Responses to the video varied in length and emphasis, with some students reflecting primarily on the subject matter, others commented directly on the nature of the production.

\section{Emergent Themes}

Cultural and practice comparisons

In terms of content, students were quite consistent in their representation of the video's messages. Points of contrast with the Northern Irish milieu tended to be reflected in feedback. Examples included references to:

the "more personal commitment” which students make in Pune;

the fact that social workers "often using their own money" to set up services; Karve students' “different learning styles”, including use of "artistic form”; the role of NGOs, including those "set up by students in India"; social workers investment of "their own money to provide... resources".

Often students' summaries of the video themes represented simplified versions of nuanced areas of the script. In some instances, these reflected students' own social outlook. Summaries of the section on unorganised labourers included:

"Unions (are) compensated for by S(ocial) Work";

"Social workers are also teachers";

"Children of labourers are taught for free”.

Some students' feedback reflects a perception that the Northern Irish system is superior and interpreted the situation in Pune as one where there is a "lack of resources", a phrase not used in the narration:

"Indian social work is a lot more deprived than I thought" 


\section{Production quality}

On the characteristics of the production, the scripted narrative received positive feedback (e.g. “Good to hear it in students' own words”), though several students suggested that more of the video be devoted to the Karve students' experience of Northern Ireland. While many students commented that they enjoyed hearing the story from the perspective of the students who participated in the exchange, some suggested that the lecturers who attended should also have been included to hear "what they learnt/what challenged them.”

Students' responses reflected a further factor which undoubtedly influenced the selection of this particular exchange as its subject, namely the aesthetic quality of the photographs. Photographs from Pune were invariably taken in bright warm sunshine often contained vivid imagery and regional dress. The subjects of the photographs are often smiling. Students' feedback described the video as “upbeat”, "bright (and) engaging” and “striking”, and included the "colour” and "positivity” among things that they liked, suggesting that these aesthetics had an impact on the audience. Several students also suggested that the video would be enhanced by having "video clips as well as photographs”.

Students often reported that the musical soundtrack inhibited the exchange participants' commentaries. This feedback was taken on board and audio levels have subsequently been remixed. Some students also advised that the narration be "more clear... and slow". The issue of narration also arose in the context of presenting the video to an audience where English was a second language, where the audience perceived regional accents of the exchange participants as difficult to understand. These comments in part reflect the tradeoff discussed earlier between professional production and familiarity with subject matter. A more skilled producer might have managed recording and editing in such a way that these technical issues did not interfere with students' experience of the video.

\section{Personal reflections}

Some students also included among things learnt, reflections by the exchange students from QUB on their subjective experience of the exchange, as well as its value in enhancing their outlook on social work. Students noted:

"The physical/mental stress on the senses from entering a new environment";

“That going abroad helps us to reflect on our own personal experiences and values”. 
In some cases, students used the things learnt field to reflect personally on their own outlook:

“Communication between different professionals- importance”;

“The need to go the extra mile when supporting individuals”.

\section{Discussion and Critical Reflection}

Underpinning the work described here is the challenge of imbuing as many students as possible with a sense of the international dimensions of social work. The principal barrier to achieving this is the scarcity of resources and ethical questions over holding programmes which asymmetrically benefit institutions from the global North. Teaching via audio-visual representation could help to bridge the resource deficit and ethical issues and to share the experience and learning of the exchange participants with peers and subsequent student cohorts. Thus, the primary objective of using this production as a pedagogical tool is to create a multiplier effect, whereby participants' first-hand experience of international dimensions can be transferred to the larger group, albeit with diminished salience. Furthermore, the video can used to demonstrate the degree to which social work is defined by its political, social and economic context and as a basis for student reflection on cultural awareness.

\section{Key Pedagogical Issues}

\section{Maintaining ethos and purpose}

A key challenge in our approach is maintaining the ethos of reciprocity and respect for diversity espoused during the exchange itself. A critical issue for social workers and social work students familiar with the welfare state model and unfamiliar with extreme poverty is avoiding the assumption that their system is more sophisticated and that their role in an exchange is to impart knowledge garnered from their superior system.

This exercise relied on the reflections of one group of student exchange participants to teach students about international social work and critical reflection. The format and content of the final production were not solely shaped by its pedagogical purpose, but also by the material available. There are limitations to using a single case study such as this to demonstrate broader principles about the global context of social work. Audiences may be 
drawn to the more immediate details of the particular milieu described, with the broader themes of internationalisation being "lost in the mix". This points to the need to springboard from such a vignette into a discussion about how the skills gained through international exchanges relate to the desirable skillset of appreciating global dimensions of social work.

Furthermore, the absence of first-hand reflections of Pune participants is a major limitation of the project and one which some students commented on. Though this was created primarily by logistical difficulties, such as obtaining a recording of comparable quality, this omission somewhat betrays an ethos of reciprocity.

\section{Challenging initial reactions}

The aim of using the novel video production described in this article in a classroom context was to "share the learning" accrued from international exchange between social work students. It is clear that this aim cannot be met solely through a short audio-visual reflection. Some responses from students reflect the ease with which important nuance can be lost and Eurocentric attitudes and beliefs reinforced rather than challenged. It is inevitable that students interpret novel material through a prism of United Kingdomcentred experience.

Nonetheless, if used correctly, this process can be used to increase appreciation for diversity. By experiencing these initial reactions to the video, classroom students are entering a process which closely mirrors the process undergone of the narrating exchange students. A skilled educator will help students to explicate and become aware of how their bias or subconscious worldviews shape their intake of information and use this discovery as the basis for self-reflection. Students' reflections suggest that, without such an accompanying discussion, the depiction of the exchange might reinforce stereotypes of international contexts, rather than challenge them.

\section{Technical Challenges}

There exists no perfect medium for transference of knowledge and reflection: much of any experience will be lost in the telling. Neither student nor mentor will recall all of what took place during an exchange, or all of the preparatory work and discussion underpinning it. In 
providing narrative, the mundane and the ambiguous are often ignored in favour of the evocative, the colourful and the anecdote-friendly.

The available materials (i.e. recorded presentations and photographs) partly shaped the project parameters, e.g., the need for and composition of the script and recorded narration, the slideshow format and the focal aspects of the exchange project. Incorporating other exchanges into a single video would have required gathering further reflections and would have been more resource intensive. The power of the visual image was harnessed in this project to highlight socials issues in both Pune and Belfast, while we relied heavily on the scripted narration to convey exchange students' critical reflections. The narrative itself was partly constrained by the photographs available. In several instances, exchange participants had been asked not to take photographs or decided against doing so, due to the sensitivity of work being carried out in Pune. Therefore, the coverage of more "gritty details" of frontline service delivery is limited to what can be shown and what images can be supplemented by narrative. Classroom students reflected positively on the images used and on their vividness and colour. There is an argument, however, that this brightness gives the video a tone of an advertisement for international exchange rather than inviting critical reflection. Some students commented that aspects of the project were under-represented and asked to see more visual evidence of "the actual work being done in India”. The principal risk of producing a longer video is that audiences will be deterred by the length. However, any length chosen requires decisions to be made on what is omitted and included.

Video production is not a widely held skill in social work education, or in academia at large. By choosing to produce the video "in house", the team prioritised familiarity with Social Work over professional production experience. The group had little experience of storyboarding or video editing prior to this project. On one hand, this approach presents a learning opportunity for those involved. On the other hand, a lack of professional slickness may distract some viewers from the substance of the script and images. Some students' feedback bore this out and educators should consider that within a diverse student group, some people will attend primarily to content and others primarily to form and style.

Furthermore, while there was widespread input into the script and the choice of images, the editing work was undertaken by a single team member. Therefore, the skills necessary to 
produce further videos are not evenly distributed through the team. Where technical media advisors are available within educational institutions, it may advisable to engage such expertise to the greatest possible extent before undertaking to 'learn by doing'. There is a clear tension around involving persons not originally party to the exchange, with the risk that nuance and sensitivity to the subject matter might be lost. This risk can be managed by continuous involvement of the original exchange participants in each stage of the production to ensure that fidelity to the original experiences is maximised.

Many students suggested that use of video footage would have been more engaging than exclusive reliance on still images. This criticism is valid, though its implications for future work are not straightforward. It can be argued that while the current project was an opportunistic and non-reactive means of using material produced in the course of the exchange. However, the dynamic of such an exchange could be greatly altered if students travel with the explicit prior aim of obtaining documentary-style video footage. This could serve to dilute the egalitarian spirit of exchange, making one group into subject and the other into investigator, thus creating barriers to a fully immersive experience of the hosts' culture.

\section{Limitations of Feedback Process}

All of the above quotations must be read with the caveat that responses were collected after showing the video at the start of a class covering international social work and related critical issues. Therefore, reactions do not reflect the sum of all learning on the topic, rather a baseline response.

A more general limitation of gathering feedback after finalising a working version of an audio-visual tool is that, unlike other teaching approaches which are amenable to continuous adjustment in response to student feedback, it is difficult and costly to make fundamental changes to an audio-visual presentation such as those suggested by some of the students (such as the inclusion of additional narrators). Therefore the greater value of the feedback exercise is to establish what additional material educators need to provide via discussion. 


\section{Conclusions and Recommendations}

The story of how new media have been adopted in the delivery of social work teaching is one of incremental progress. At each stage, the question is rightly asked 'is this mode of learning a good fit with the learning objectives at hand?' In the case of educating a globally-minded social work, the use of digital media to represent challenges and opportunities of diversity and international practices appears an efficient compliment to facilitating international exchanges. For the many students unable to undertake travel due to personal circumstances and scarce resources, it is helpful to share in the experience through as many senses as possible. However, students' reflections underscore the importance of incorporating critical and reflexive discussion around the presentation of video material on international social work.

The production aimed to ignite students' curiosity of cultural diversity, provide an awareness of issues of poverty, social justice and community social work and facilitate an understanding of the different contexts of social work practice. While it was not intended to be seen, as Keddell describes, as an "unproblematic representation of the real world" (2011, p.402) , or as a basis for comparing work practice between India and the United Kingdom (given the inherent imperialism of such an approach) not all students were able to immediately reflect more generally on the themes presented in the video. Many students had difficulty going beyond a simplistic comparison of British and Indian social work. There is clearly a tension in trying to present an account which is personal, critical, which educates viewers on both the challenges and benefits of international exchange, and which is accessible to diverse audiences. It is important that, in discussing how to promote awareness of cultural diversity, that we remain cognisant of the diversity represented in a given student group. Worldviews, learning styles and needs will vary widely within a group and the effectiveness of any tool will differ from learner to learner. Without thorough and inclusive discussion aimed at promoting critical reflection and challenging unconscious bias, there is risk of stereotyped understandings of international contexts and practices being reinforced rather than challenged, due to the inherent limitations of audiovisual (and indeed all) media. 


\section{References}

Abrams, L.S. \& Moio, J.A. (2009), Critical race theory and the cultural competence dilemma in social work education, Journal of Social Work Education, 45 (2), 245-261.

Ballantyne, N. (2008). Multimedia learning and social work education. Social Work Education, 27(6), 613-622.

Betancourt, J.R., Green, A.R., Carrillo, J.E. and Ananeh-Firempong, O. (2003). Defining cultural competence: A practical framework for addressing racial/ethnic disparities in health and health Care, Public Health Reports, 118, 293- 302.

Ben-Ari, A., \& Strier, R. (2010) 'Rethinking cultural competence: What can we learn from Levinas?’. British Journal of Social Work, 40 (7), 2155-2167.

Bolger, J. (2014). Video self-modelling and its impact on the development of communication skills within social work education. Journal of Social Work, 14(2), 196-212.

Campbell, J., Duffy, J., Traynor, C., Coulter, S., Reilly, I. \& Pinkerton, J. (2012). Social work education and political conflict: preparing students to address the needs of victims and survivors of the Troubles in Northern Ireland, European Journal of Social Work, 16 (4), 506-520.

Carter-Anand, J., \& Clarke, K. (2009). Crossing borders through cyberspace: A discussion of a social work education electronic exchange pilot project across the Atlantic. Social Work Education, 28(6), 583-597.

Cox, D. \& Pawar, M. (2006). International Social Work. London: Sage. 
Chau, R.C.M., Yu, S.W.K., \& Tran, C.T.L. (2011). The diversity based approach to culturally sensitive practices. International Social Work, 54 (1), 21-33.

Council on Social Work Education (CSWE) (2001). Educational Policy and Accreditation Standards, Alexandria: Council on Social Work Education.

Das, C., \& Carter-Anand, J. (2014). Strategies for critical reflection in international contexts for social work students. International Social Work, 57(2), 109-120.

Department of Health, Social Services and Public Safety (2012) Improving and safeguarding social wellbeing: a strategy for social work in Northern Ireland 2012-2022 Belfast DHSSPS

Ferguson, I. (2004). Neoliberalism, the third way and social work: The UK experience. Social Work \& Society, 2(1), 1-9.

Ferguson, I., \& Smith, L. (2012). Education for change: Student placements in campaigning organisations and social movements in South Africa. British Journal of Social Work, 42(5), 974-994.

Fook, J. (2002). Social work: Critical theory and practice. London, UK: Sage.

Fook, J., \& Askeland, G. A. (2007). Challenges of critical reflection:'Nothing ventured, nothing gained’. Social Work Education, 26(5), 520-533.

Fukkink, R. G., Trienekens, N., \& Kramer, L. J. (2011). Video feedback in education and training: Putting learning in the picture. Educational Psychology Review, 23(1), 45-63. 
Gray, M. (2005). Dilemmas of international social work: Paradoxical processes in indigenisation, universalism and imperialism. International Journal of Social Welfare, 14(3), 231-238.

Harrison, G., \& Turner, R. (2011). Being a "culturally competent" social worker: making sense of a murky concept in practice. British Journal of Social Work , 41(2), 333-350.

Healy, L. M. (2008). International social work: Professional action in an interdependent world. Oxford, UK: Oxford University Press.

Healy, L. M. \& Link, R.J. (2012) Models of Internationalizing Curriculum in Healy LM and Link RJ (eds) Handbook of International Social Work. Oxford University Press.

Higher Education Academy (2014) Internationalising the Curriculum. York: Higher Education Academy.

Houston, S. (2008). Transcending ethnoreligious identities in Northern Ireland: Social work's role in the struggle for recognition. Australian Social Work, 61(1), 25-41.

Ife, J. (2008) Human Rights and Social Work: Towards Rights-Based Practice, Port Melbourne, Cambridge University Press.

Jamrozik, A. (2009). Social Policy in the Post-Welfare State (3rd ed.). French’s Forest, NSW: Pearson Education Australia.

Jones, R. (2014). The best of times, the worst of times: Social work and its moment. British Journal of Social Work, 44 (3): 485-502.

Kumagai, A., \& Lypson, M. (2009). Beyond cultural competence: critical consciousness, 
social justice, and multicultural education’. Academic Medicine, 84(6),

$782-787$.

Keddell, E. (2011). A constructionist approach to the use of arts-based materials in social work education: Making connections between art and life. Journal of Teaching in Social Work, 31(4), 400-414.

Lager, P. \& Mathiesen, S. (2012) International Field Placments in Healy, L.M. and Link, R.J. (eds) Handbook of International Social Work. Oxford University Press.

Laird, S. (2008) Anti-Oppressive Social Work: A Guide for Developing Cultural Competence. London: Sage.

Levin, S., Whitsett, D., \& Wood, G. (2013). Teaching MSW social work practice in a blended online learning environment. Journal of Teaching in Social Work, 33(4-5), 408-420.

Link, R.J. \& Vogrincic, G.C. (2012). Models of International Exchange in Healy, L.M. and Link, R.J. (eds) Handbook of International Social Work. Oxford University Press.

Lorenz, W. (1997) Social Work in a Changing Europe, Keynote paper presented at the IFSW/EASSW Conference Culture and Identity: Social Work in a Changing Europ. Dublin: University College Dublin.

Merrill, M. C., \& Frost, C. J. (2011). Internationalizing Social Work Education: Models, Methods and Meanings. Frontiers: The Interdisciplinary Journal of Study Abroad, 21, 189-210. 
Okech, D., Barner, J., Segoshi, M., \& Carney, M. (2014). MSW student experiences in online vs. face-to-face teaching formats? Social Work Education, 33(1), 121-134.

Pinkerton, J., \& Campbell, J. (2002). Social work and social justice in Northern Ireland: Towards a new occupational space. British Journal of Social Work, 32(6), 723-737.

Payne, M. \& Askeland, G.A. (2008) Globalization and International Social Work - Postmodern Change and Challenge. Surrey: Ashgate.

Regan, J.A.R.C., \& Youn, E. J. (2008). Past, present, and future trends in teaching clinical skills through web-based learning environments. Journal of Social Work Education, 44(2), 95115.

Wehbi, S. (2008). Teaching international social work: A guiding framework. Canadian Social Work, 25(2), 117-132.

Williams, C. F., \& Soydan, H. (2005). When and how does ethnicity matter? A cross-national study of social work responses to ethnicity in child protection cases. British Journal of Social Work, vol. 35(6), 901-920. 